\title{
ADVANCES IN THICK FILM CONDUCTORS FOR MICROWAVE INTEGRATED CIRCUITS
}

\author{
R. WAYNE JOHNSON, PHIL W. RICH, DEBBIE D. RICH and LARRY K. WILSON \\ Department of Electrical and Biomedical Engineering, Vanderbilt University, Nashville, Tennessee USA
}

(Received August 24, 1979)

\begin{abstract}
New conductor pastes have made possible great improvements in the loss characteristics of thick film microwave integrated circuits. This paper presents data on the microwave characteristics of transmission structures made from newly developed copper, silver and gold conductor pastes on alumina and garnet substrates. The resistivity and microstructure for each conductor material was examined for correlation with microwave properties. These data show that thick film circuits can give excellent performance through $18 \mathrm{GHz}$.
\end{abstract}

\section{INTRODUCTION}

It is well known that thick film circuits can provide significant cost advantages over thin film circuits. Until recently, however, thin film has been the dominant technology for microwave integrated circuits. ${ }^{1}$ This is due in part to the many comparative studies of the microwave losses of thick and thin film conductors which have generally shown that above about $4 \mathrm{GHz}$, thin films are much less lossy. ${ }^{2,3}$ Although some studies have given favorable reports on thick films for microwave use $^{4}$ their conclusions have generally been either that thin films are preferred or that thick film circuits must be etched in order to give satisfactory low losses.

The advent of new fritless and low frit thick film conductor pastes has made possible great improvements in the loss characteristics of screen printed thick film microwave integrated circuits. This paper presents data on microwave transmission lines made using recently developed copper, silver and gold conductor pastes on a variety of substrate materials.

\section{TRANSMISSION LINES}

Microstrip transmission lines $\left(Z_{0}=50 \mathrm{ohm}\right)$ were screen printed on two-inch square substrates with 325 mesh screens. The substrate materials included $96 \%$ and $99.5 \%$ purity alumina and Trans-Tech G-113 yttrium iron garnet with surface roughness of both 10 and 20 microinches. Four commercially available conductor pastes were used; these were Dupont 9922 copper, Cermalloy 7029d copper, Dupont 4019 gold and Thick Film Systems 4055 silver. The attenuation of each line was measured directly over the frequency range from 2 to $18 \mathrm{GHz}$. The data thus includes any losses associated with the SMA to microstrip transitions used. Pressure contacts were used to make connections between the microstrip and the connectors.

TABLE I

Transmission line characteristics

\begin{tabular}{lll}
\hline Paste & $\begin{array}{l}\alpha \mathrm{dB} / \mathrm{cm} \\
\text { at 12 GHz }\end{array}$ & $\begin{array}{l}\text { DC Resistance } \\
\Omega / \mathrm{cm}\end{array}$ \\
\hline TFS 4055 Silver & 0.15 & 0.029 \\
Cermalloy 7029d Copper & 0.16 & 0.023 \\
Dupont 9922 Copper & 0.20 & 0.023 \\
Dupont 4019 Gold & 0.23 & 0.048 \\
\hline
\end{tabular}

The best materials for transmission lines were found to be the Thick Film Systems silver paste and Cermalloy copper. For comparison, the lowest DC resistance was obtained with the Dupont and Cermalloy copper pastes. A representative data sample is shown in Table I where the attenuation of 25 mil wide lines on $96 \%$ purity alumina at $12 \mathrm{GHz}$ is given. The corresponding DC resistance as measured with Kelvin probes is also given. Interestingly, the gold paste gave the poorest loss performance of the pastes studied contrary to earlier expectations. ${ }^{5,6}$

Figures 1-5 show the loss characteristics of Dupont 9922 copper lines on the four substrates. 


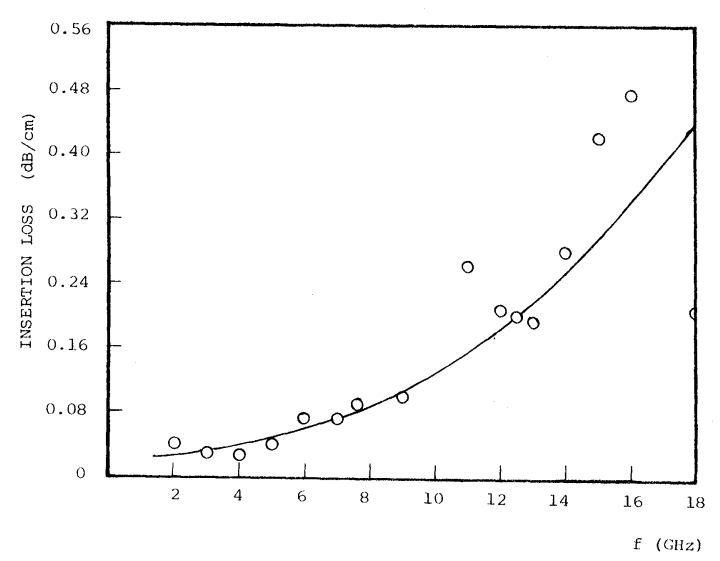

FIGURE 1: Transmission line insertion loss Dupont $9922 \mathrm{Cu}$ on $96 \%$ alumina.

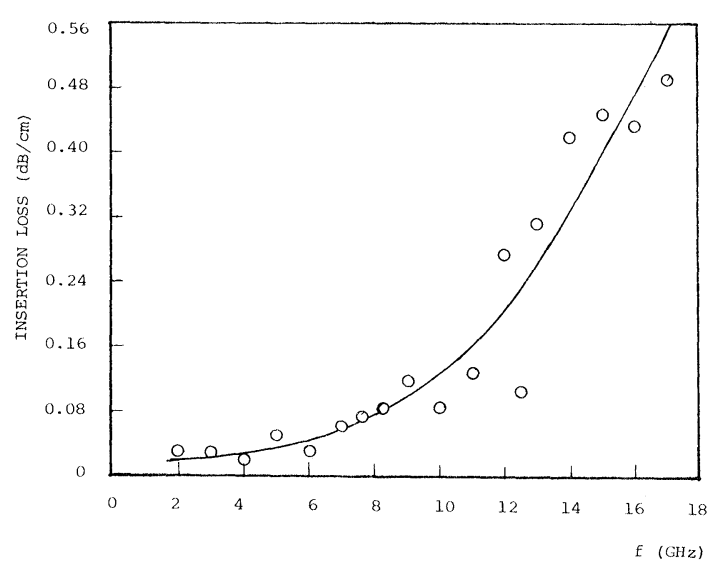

FIGURE 2: Transmission line insertion loss Dupont $9922 \mathrm{Cu}$ on $99.5 \%$ alumina.

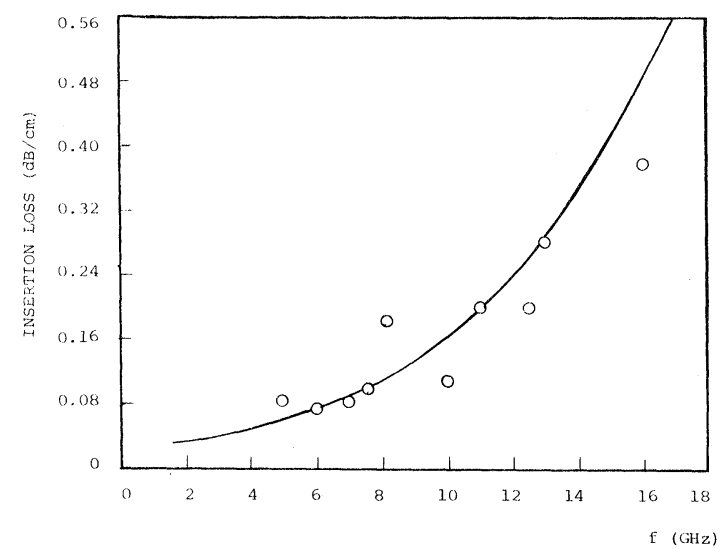

FIGURE 3: Transmission line insertion loss Dupont $9922 \mathrm{Cu}$ on unpolished YIG.

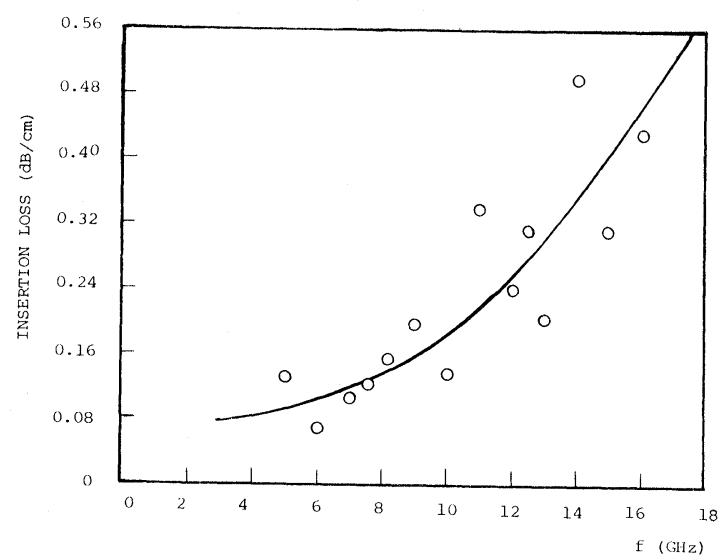

FIGURE 4: Transmission line insertion loss Dupont $9922 \mathrm{Cu}$ on polished YIG.

At first glance it appears that the loss on $96 \%$ alumina is less than that on $99.5 \%$ alumina. If the comparison is made on the basis of attenuation per wavelength, however, they appear about the same. A comparison of the losses in copper thick film lines with experimental copper and gold thin film lines and with theoretical bulk metal lines are shown in Figure 5.

Theoretically, the loss of a bulk metal microstrip line is proportional to the square root of frequency. ${ }^{7}$ The rapid rise of our data at higher frequencies does not agree with the theory. The mechanism causing this extra loss in thin-film microstrip is generally attributed to radiation or surface wave generation. ${ }^{8-9}$ Another contributing factor in molecularly bonded thick film is conduction in the reactive layer which bonds the metallization to the substrate.

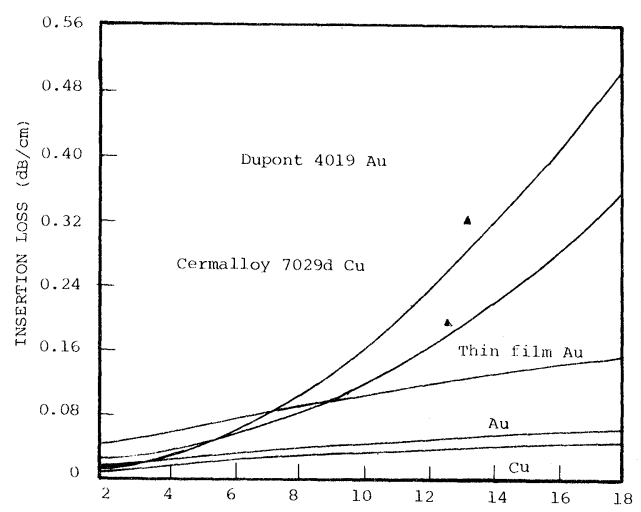

FIGURE 5: Comparison of thick film $\mathrm{Cu}$ and $\mathrm{Au}$, thin film $\mathrm{Au}$, and bulk metal losses. 


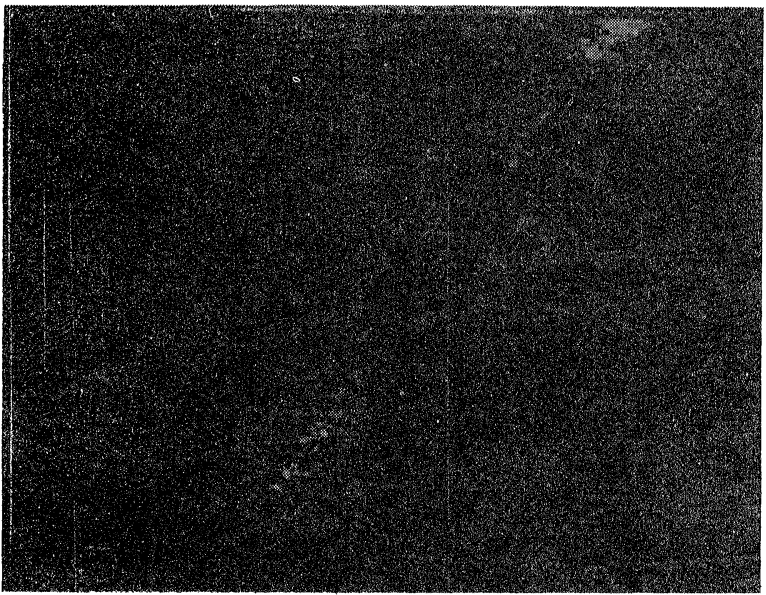

FIGURE 6: Micrograph of substrate with Au conductor removed.

To determine the elements involved in one type of reactive bond, mercury was used to remove Dupont 4019 gold which had been fixed on an unpolished alumina substrate. Figure 6 shows a scanning electron micrograph of the substrate with the metallization removed. Utilizing energy dispersive $\mathrm{X}$-ray analysis technique, the elements bismuth and cadmium were found on the substrate surface.

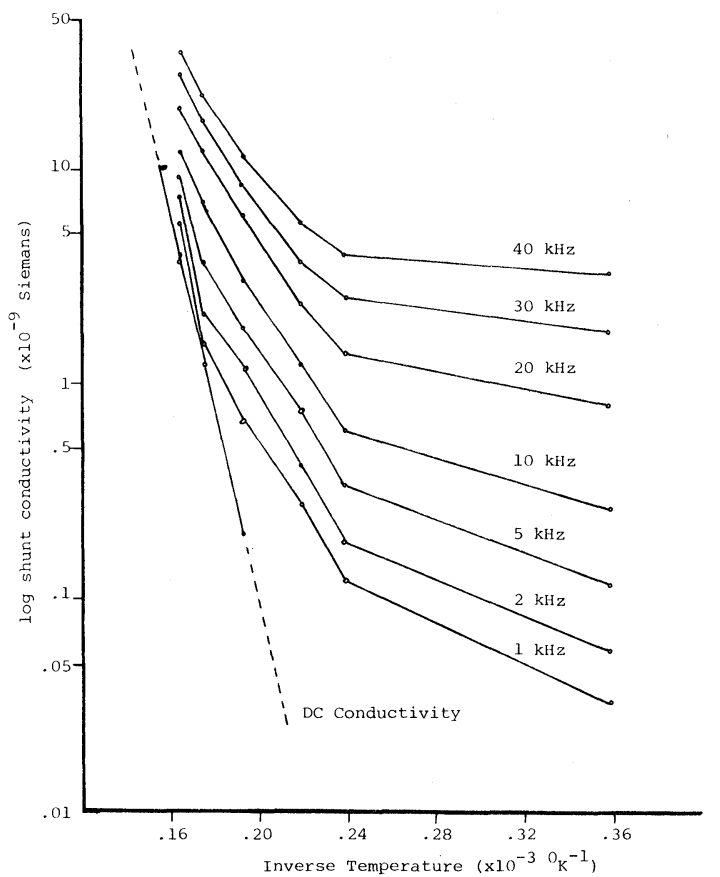

FIGURE 7: Plot of $\log$ shunt conductivity vs. Inverse Temperature.

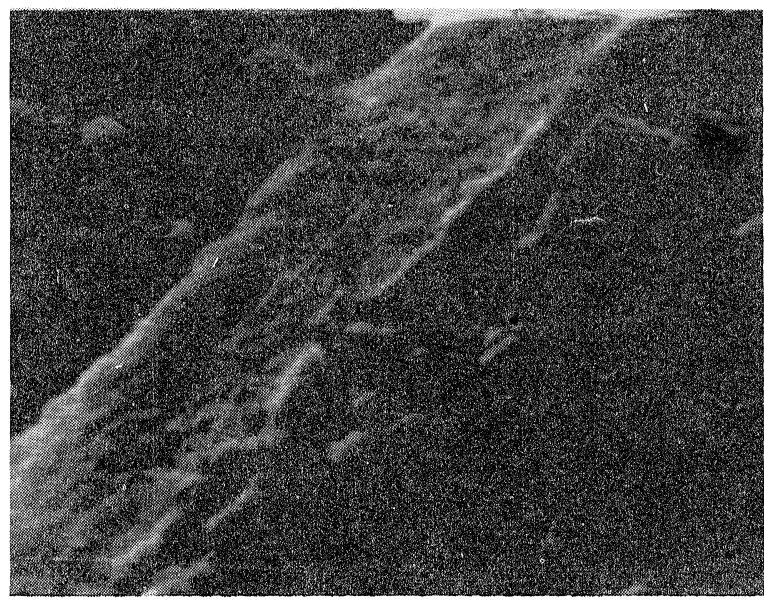

FIGURE 8: Micrograph of Dupont $4019 \mathrm{Au}$ on alumina.

Low-frequency conductivity studies have revealed that the shunt conductance between the reactively bonded conductor through the substrate material to the reactively bonded ground plane is indeed strongly frequency dependent. Figure 7 shows a plot of the shunt conductivity as a function of inverse temperature with frequency as a parameter. The semiconductivity character of the bondsubstrate-bond path is clearly evident. The frequency dependence, even at low frequencies, is sufficiently strong to indicate a considerably higher loss in the microwave region that would be predicted by a simple dielectric loss mechanism. Research to further eliminate the loss at the molecular bonded conductive paste/dielectric interface is being continued.

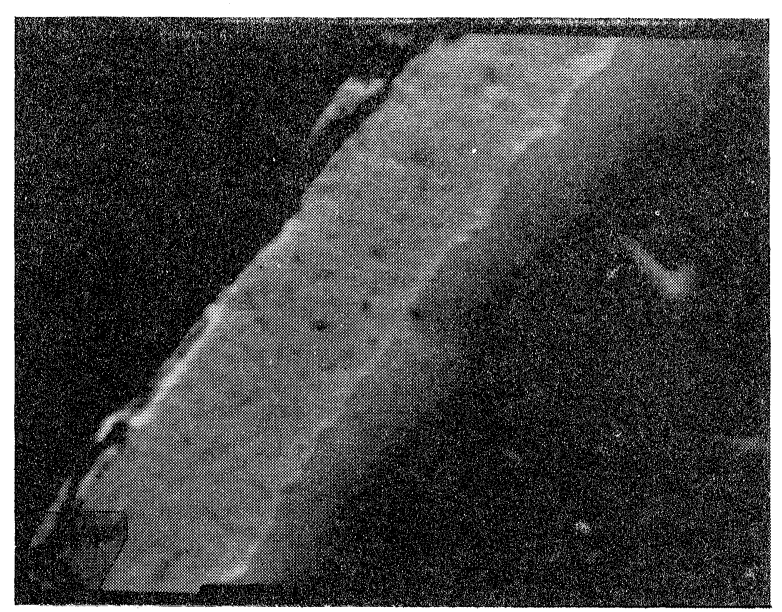

FIGURE 9: Micrograph of Dupont $4019 \mathrm{Au}$ on YIG. 
Polished cross section of transmission lines were examined with a scanning electron microscope (SEM). Figures 8 and 9 show micrographs of Dupont 4019 gold on unpolished alumina and YIG. These micrographs are typical of the many photographs taken of the various paste-substrate combinations. The major difference is the porosity of the alumina as compared to the YIG.

\section{CONCLUSION}

This paper has demonstrated that the microwave loss in molecularly bonded thick-film microstrip transmission lines is quite comparable to losses in thin-film microstrip. The loss at the reactivelybonded paste/dielectric interface has been examined. It is concluded that thick-film conductors can provide an excellent cost/performance trade-off through $18 \mathrm{GHz}$.

\section{REFERENCES}

1. M. Caulton, Film Technology for Microwave Integrated Circuits, Proc. IEEE, October 1971, pp. 1481-1489.

2. F. Z. Keister, An Evaluation of Materials and Processes for Microwave Integrated Circuits, IEEE Trans MTT-16, July 1968 , pp. 469-75.

3. H. Sobol, A Review of the Technological and Electromagnetic Limitations of Hybrid Circuits for Microwave Applications, IEEE Trans PHP-8, June 1972, pp. 59-66.

4. J. P. Ramy et al., Optimization of the Thick and Thin Film Technologies for Microwave Circuits on Alumina and Fused Silica Substrates, IEEE Trans $M T T-26$, October 1978, pp. 814-820.

5. P. Sayers, Molecular Bonding Conductive Films, Solid State Tech., September 1974, pp. 66-69.

6. R. Waugh, D. LaCombe, and J. Garcia, Microwave Integrated Circuits Using Thick and Thin Film Technologies, Solid State Tech., April 1973.

7. R. A. Pucel et al., Losses in Microstrip, IEEE Trans $M T T-16$, June 1968 , pp. $342-50$.

8. A. F. Hinte, G. V. Kopcsay and J. J. Taub, Choosing Transmission Line, Microwaves, December 1971 pp. 46-50.

9. C. P. Hartwig, M. P. Lepie, D. Masse, A. E. Paladino, and R. A. Pucel, Microstrip Technology, 1969 G-MTT Int. Symp. Digest, pp. 314-15. 

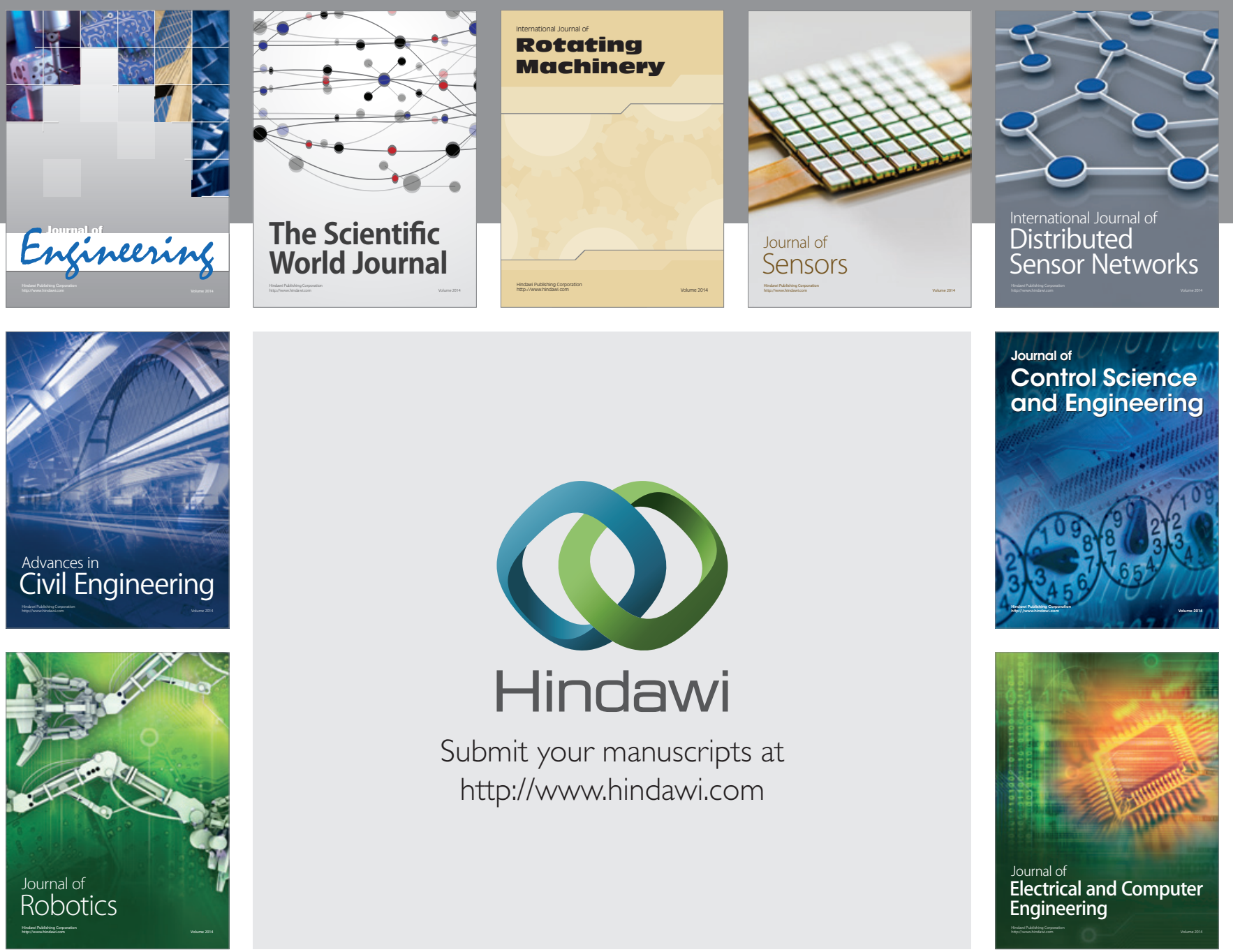

Submit your manuscripts at

http://www.hindawi.com
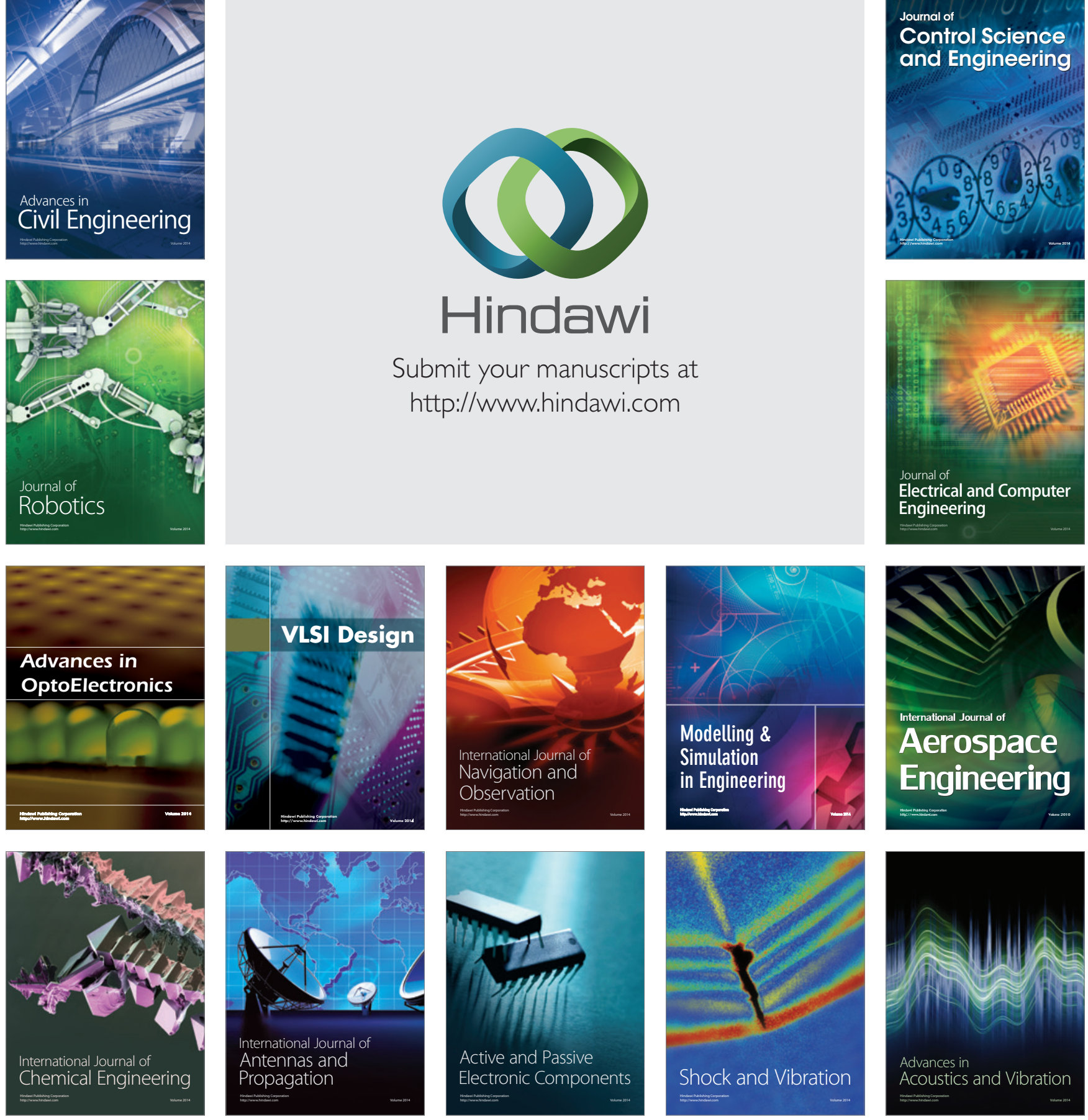